\title{
Long term complications of orbital floor fracture repair
}

\author{
Patrick R Boulos MD ${ }^{1}$, Patrick G Harris MD CM FRCSC ${ }^{2}$, Carlos Cordoba MD FRCSC $^{2}$, \\ Hugo Ciaburro MD FRCSC ${ }^{2}$, Gilles Frenette MD FRCSC ${ }^{2}$ \\ ${ }^{1}$ Department of Ophthalmology, Hôpital Maisonneuve-Rosemont, Université de Montréal, ${ }^{2}$ Division of \\ Plastic Surgery, Department of Surgery, Centre Hospitalier de l'Université de Montréal (CHUM), \\ Hôpital Notre-Dame, Montreal, Quebec
}

\section{PR Boulos, PG Harris, C Cordoba, H Ciaburro, G Frenette. Long term complications of orbital floor fracture repair. Can J Plast Surg 2001;9(5):183-192.}

PURPOSE: To search for complications of orbital floor fracture repair that occur late postoperatively, to reveal their natural course and to attempt to associate the complications with variables that are possibly involved in their genesis.

METHODS: A retrospective comparative case series of all orbital floor fracture repair cases (158 eyes) from 1983 to 1998 was done. Synthetic prostheses were tailored to the orbital floor in clinically significant fractures. Bone grafts were chosen for large defects, comminuted fractures or if other reconstruction (eg, sinus) was required.

Variables studied included age, sex, trauma to surgery time lag, surgeon, fracture type, length of surgery, antibiotics, prosthesis material, hospital stay and follow-up. These variables were tested for association with the following complications: altered vision, diplopia, dysesthesia, ectropion, pain, infection, enophthalmos and extrusion. Occurrence and resolution data were collected.

RESULTS: One of four complications (often more than one per eye) resolved without surgery. Reintervention resolved one of three complications. Of all patients, $39.2 \%$ remain with long term unresolved complications.

Altered vision is more probable with older patients and with longer surgeries. Diplopia was least likely to occur with orbitozygomatic or panfacial fractures and more probable with bone grafts. Ectropion and epiphora increased with a fracture's severity. Pain was mostly attributable to bone grafts. Enophthalmos was mainly due to large or comminuted fractures. Infection and extrusion were rare. Sex, surgeon and trauma to surgery time lag had no bearing on the incidence of complications.

CONCLUSIONS: Delaying surgery did not seem to influence complications. Lessening ocular manipulation during longer surgeries may reduce vision changes. The only truly modifiable variable was the material used for orbital floor repair. Alloplastic prostheses should be used, but if large or comminuted fractures are involved, bone grafting is an interesting first choice.

Key Words: Blow-out; Complication; Fracture; Long term; Orbit; Surgery

\section{Réparations des fractures du plancher de l'orbite-complications à long terme}

BUT : Relever les complications tardives des réparations chirurgicales des fractures du plancher de l'orbite, comprendre leur évolution spontanée et tenter d'associer les complications à des variables susceptibles d'être mises en cause dans leur genèse.

MÉTHODE : Nous avons mené une étude comparative, rétrospective de tous les cas de réparation de fracture du plancher de l'orbite (158 yeux), enregistrés entre 1983 et 1998. Des prothèses synthétiques, adaptées au plancher de l'orbite, ont été posées dans les cas de fracture cliniquement significative. Les greffes osseuses ont été l'option retenue dans les cas de lésion étendue, de fracture comminutive ou de reconstruction d'autres parties, par exemple les sinus.

Les variables choisies comprenaient l'âge, le sexe, le temps écoulé entre le traumatisme et l'intervention chirurgicale, le chirurgien, le type de fracture, la durée de l'intervention, l'antibiothérapie, le matériau utilisé pour les prothèses, la durée du séjour à l'hôpital et le suivi. Nous avons tenté d'associer ces variables aux complications suivantes : vision altérée, diplopie, dysesthésie, ectropion, douleur, infection, énophtalmie et extrusion de prothèse. Des données ont été recueillies sur la fréquence et la disparition de ces complications.

RÉSULTATS : Une complication sur quatre (souvent plus d'une par œil) est disparue sans intervention chirurgicale. Une nouvelle intervention a permis de corriger une complication sur trois. Dans 39,2\% des cas, les complications à long terme ont persisté.

Correspondence: Dr Patrick G Harris, Division of Plastic Surgery, Centre Hospitalier de l'Université de Montréal (CHUM), Hôpital Notre-Dame, 1560 Sherbrooke East, Montreal, Quebec H2L 4M1. Telephone 514-890-8000 ext 23757 
La vision trouble se rencontrait plus souvent chez les patients âgés et dans les cas de chirurgie prolongée. La diplopie était moins susceptible de se produire dans les cas de fracture panfaciale ou orbito-zygomatique et plus susceptible, dans les cas de greffe osseuse. La fréquence de l'ectropion et de l'épiphora augmentait avec la gravité des fractures. La douleur était surtout attribuable aux greffes osseuses. L'énophtalmie était principalement due aux fractures de grande taille ou aux fractures comminutives. Quant aux infections et à l'extrusion de prothèse, elles ont été rarement observées. Aucun lien n'a été établi entre le sexe, le chirurgien ou le temps écoulé entre le traumatisme et l'intervention chirurgicale, et l'incidence des complications.

CONCLUSIONS : Le fait de retarder l'intervention chirurgicale n'a pas semblé avoir d'influence sur les complications. La diminution de la manipulation des yeux au cours des interventions prolongées peut réduire les changements de vision. La seule variable vraiment modifiable s'est avérée le matériau utilisé pour les réparations du plancher de l'orbite. La prothèse en matériau alloplastique est préférable aux autres mais, dans les cas de fracture de grande taille ou de fracture comminutive, la greffe osseuse est un premier choix interessant.

$\mathrm{T}$ he majority of patients who suffer orbital floor fractures that require repair follow a smooth recovery course free of problems. Unfortunately, about one of three patients in the present case series of orbital floor fracture repairs faced complications postoperatively. A search for complications that occurred very late in the postoperative period was conducted. The present study attempts to reveal the natural course of these complications from occurrence to resolution. It also attempts to associate the complications with a variety of variables that are possibly involved in their genesis.

\section{PATIENTS AND METHODS}

A retrospective chart review of all orbital floor fracture repair cases (158 eyes) seen at the Centre Hospitalier de l'Université de Montréal (CHUM), Hôpital Notre-Dame, from April 1983 to June 1998, spanning over 15 years, was conducted. Data based on plastic and ophthalmology consultations were collected in two parts. Charts from 1983 to 1992 were read by an author to study the teflon prosthesis in orbital floor fractures (1). Patient files from 1992 to 1998 were reviewed by another author.

\section{Variables}

Variables studied included the following: age, sex, trauma to surgery time lag, surgeon (four surgeons), fracture type, length of surgery, antibiotic prophylaxis, type of prosthesis material, length of hospital stay and duration of follow-up.

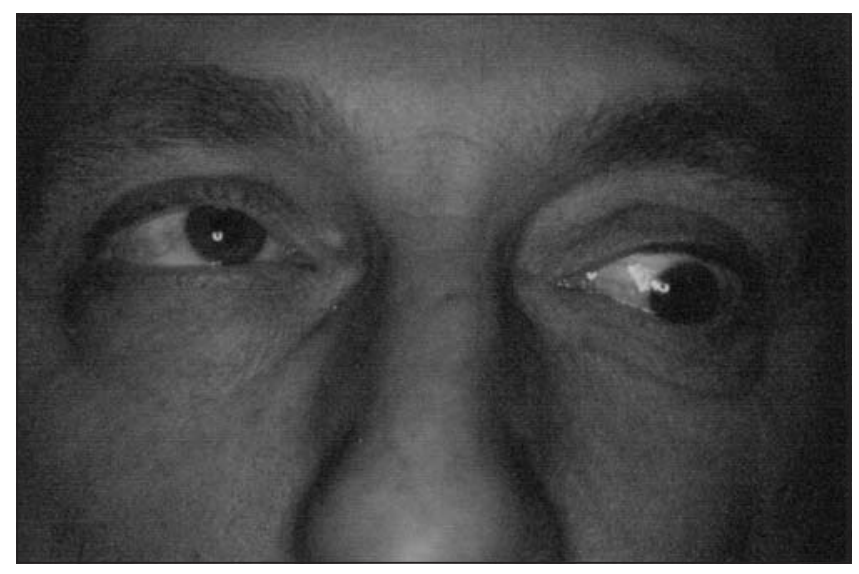

Figure 1) Diplopia secondary to upgaze restriction in left eye (inferior rectus entrapment)
Fracture types were separated into three groups (according to computed tomography [CT] scan assessment by radiologists): isolated orbital floor fractures; orbitozygomatic or panfacial fracture; and large or comminuted fracture (a fracture was considered to be large if it extended to the inferior orbital fissure or if a radiologist or plastic surgeon found that it encompassed most of the orbital floor).

Antibiotic prophylaxis included two possibilities: topical or no prophylaxis, and systemic antibiotic.

Prostheses were placed into three groups: teflon or silastic; bone graft; and metallic plate or grill and others.

\section{Complications}

Information was also gathered about the complications that ensued, the time of first mention of the complications in the patient file (when the patient was first queried about these symptoms) and how they were resolved. A complication was defined as any problem that appeared after surgery, or was present before surgery and should have been corrected by surgery.

Altered vision was one of eight possible complications. It included refractive errors (three eyes), cataracts (two eyes), glaucoma (one eye), optic atrophy (two eyes), central retinal artery occlusion (one eye), preretinal (one eye) or retrobulbar hemorrage (one eye), and other complications (three eyes). A complication was noted only if it was ipsilateral to the trauma. Bilateral conditions were excluded.

Diplopia or new onset orthoptic anomalies, and two cases of cranial nerve III or IV paresis qualified for the category of diplopia complications (while knowing the latter had only a slim chance of being resolved by surgery). Problems that spontaneously disappeared within the first 10 postoperative days were excluded because they probably resulted from edema (Figure 1).

Dysesthesia complications of the maxillary area was also excluded if it was only present in the first 10 days following surgery.

Ectropion and epiphora were grouped in the same category because in most cases they were related. Also included in this category is unilateral dry-eye (five eyes) (Figure 2).

Pain in the eye or stiffness in the surrounding tissues and unilateral headache were included in the category of pain complications. The pain was sometimes associated with exposure to cold (two eyes) or with nose blowing (one eye). 


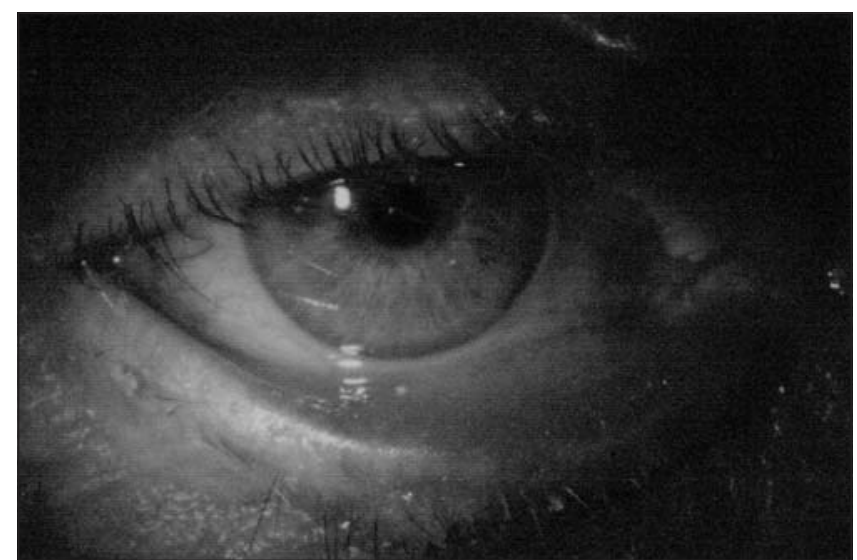

Figure 2) Ectropion of the lower eyelid secondary to postsurgical fibrosis

Infection complications occurred in three forms: bacterial conjunctivitis (three eyes), unilateral sinusitis (two eyes) and orbitomaxillary sinus fistula (one eye).

Enophtalmos and extrusion were the last two categories of complications (Figure 3).

Because the objective of the present study was to discover the long term complications of orbital floor fracture repair, and because for most cases, outpatient follow-up seldom lasted more than five years (usually about one year), additional information was gathered by a telephone survey. All patients whose last chart review indicated ongoing complications or who had not been seen in over one year were called. One hundred thirty-four calls were placed, and 39 patients were reached. The other patients no longer had the same phone number, could not be located through the white pages or were incarcerated. The patients were asked about all of the above complications and any other postoperative complaint.

\section{Operative technique}

Under general anesthesia and local infiltration with lidocaine and adrenaline, a subciliary palpebral or subtarsal incision was performed. The orbital floor was explored through these incisions or local lacerations. When orbital floor defects were clinically significant (eg, displaced, involved the loss of substance...), an appropriately sized prosthesis was tailored to the orbital floor and placed behind the infraorbital rim. Bone grafts were mainly chosen when the fracture was comminuted, the defect was large or if other bony reconstruction was required (eg, sinus). Donor sites included the iliac crest, ribs and maxilla. Calvarial bone grafts were not used. Closure was achieved in the periosteum or orbicularis layers, usually with polyglycolic acid (Dexon 3-0, 4-0 or 5-0; Cyanamid Canada Inc, Canada).

\section{STATISTICAL ANALYSIS}

Logistic regression was used to test the influence of the variables studied (eg, age) on the probability of each complication. The logistic model linked the probability of a complication to the independent variables under study in a regression formula. Because detecting a complication was more probable if patients were followed for a longer period

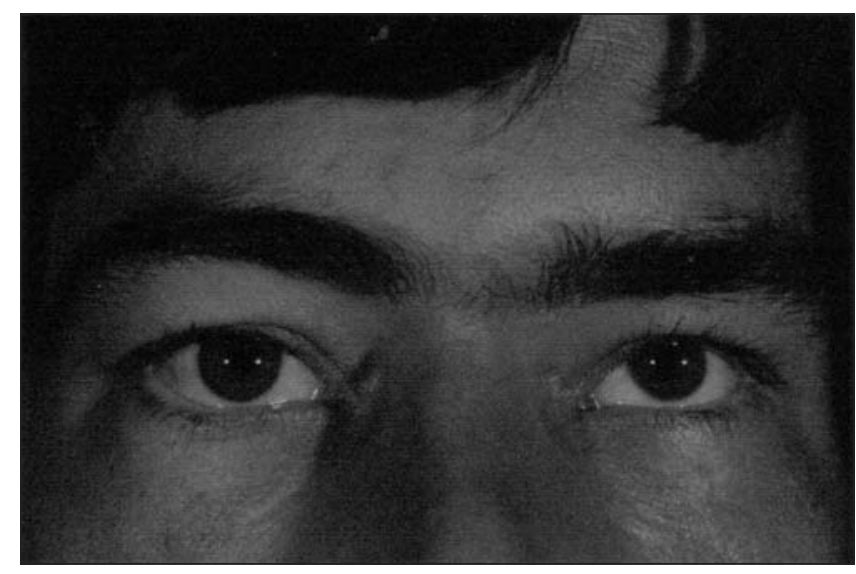

Figure 3) Enophthalmos of the left eye secondary to the loss of orbital floor support

of time, the time of follow-up was included in all models as an independent variable. A logistic model was first adjusted with follow-up as the only variable, after which each variable studied was added separately to the model to see if its influence on the probability of a complication was significant. $\mathrm{P}<0.05$ was used to assess statistical significance. Odds ratio (OR) (adjusted for time of follow-up) compared the risks of complication under different conditions. Because of insufficient cases, logistic regression was not used in the OR calculations of the infection complications.

\section{Variables}

\section{RESULTS}

A total of 241 patients presented with orbital floor fractures. All patients who did not require repair with a prosthesis or graft were rejected from the presentation. Thus, 149 patients (158 eyes) were included. Calculations performed with both of the latter numbers produced identical results. The analyses described in the present article use 158 eyes as the denominator (Table 1).

Patient ages ranged from 13 to 79 years for a mean of 35.9 years. There were 122 male eyes $(77.2 \%)$ and 36 female eyes $(22.8 \%)$. Fractures occurred almost equally in the right $(50.6 \%)$ and left $(49.4 \%)$ eyes. Orbitozygomatic or panfacial fractures were the most frequent $(71.5 \%)$. Isolated orbital floor fractures were found in $16.5 \%$ of cases, and $12.0 \%$ of the fractures were large or comminuted.

The median value for trauma to surgery time lag was seven days. Delays ranged from zero to 152 days. Four surgeons operated on the patients; two of these surgeons were responsible for $69.7 \%$ of the eyes. The surgeries lasted $2 \mathrm{~h}$ and $39 \mathrm{~min}$, on average, with durations ranging from one-half hour to $12 \mathrm{~h}$. Orbital floor support consisted of teflon or silastic prostheses in 138 cases $(87.3 \%)$ and metallic prosthesis or other materials in 12 cases $(7.6 \%)$. Bone grafts were used only eight times (5.1\%). Subjects received systemic antibiotics $77.8 \%$ of the time (usually cefazolin sodium [Ancef; Smithkline Beecham, Canada] 1 g intravenously every $8 \mathrm{~h}$ or clindamycin hydrochloride [Dalacin C; Abbott, Canada] $600 \mathrm{mg}$ intravenously every $8 \mathrm{~h}$ for approximately three doses). 
TABLE 1

Summary of variables studied in patients with orbital floor fracture repairs seen at Centre Hospitalier de l'Université de Montréal, Hôpital Notre-Dame between 1983 and 1992

\begin{tabular}{|c|c|c|c|c|c|c|c|}
\hline Variable & $\begin{array}{c}\text { Number of } \\
\text { eyes }\end{array}$ & $\%$ & $\begin{array}{l}\text { Maximum } \\
\text { value }\end{array}$ & $\begin{array}{l}\text { Median } \\
\text { value }\end{array}$ & $\begin{array}{l}\text { Minimum } \\
\text { value }\end{array}$ & Mean & SD \\
\hline Age & 158 & & 79 & 34 & 13 & 35.9 & 13.5 \\
\hline Male & 122 & 77.2 & & & & & \\
\hline Female & 36 & 22.8 & & & & & \\
\hline \multicolumn{8}{|l|}{ Side } \\
\hline Left & 78 & 19.1 & & & & & \\
\hline Trauma to surgery time lag & 158 & & 152 days & 7 days & 0 days & 11.5 days & 15.8 days \\
\hline \multicolumn{8}{|l|}{ Surgeon } \\
\hline A & 10 & 6.3 & & & & & \\
\hline B & 54 & 34.2 & & & & & \\
\hline \multicolumn{8}{|l|}{ Type of fracture } \\
\hline $\begin{array}{l}\text { Isolated orbital floor } \\
\text { fracture }\end{array}$ & 26 & 16.5 & & & & & \\
\hline $\begin{array}{l}\text { Orbitozygomatic or } \\
\text { panfacial }\end{array}$ & 113 & 71.5 & & & & & \\
\hline Large or comminuted & 19 & 12.0 & & & & & \\
\hline \multicolumn{8}{|l|}{ Antibiotic prophylaxis } \\
\hline None or topical & 35 & 22.2 & & & & & \\
\hline Systemic & 123 & 77.8 & & & & & \\
\hline \multicolumn{8}{|l|}{ Type of material } \\
\hline
\end{tabular}

The median length of hospital stay was three days, with durations spanning zero to 482 days. Having defined follow-up as the time elapsed between surgery and the last recorded visit or the telephone survey, a median value of 299.5 days (almost one year) was obtained. Patients were followed from postoperative day one to a maximum of 5834 days postoperatively (almost 16 years). When duration of follow-up was determined by the most recent medical visit, a median value of 123.5 days was found.

\section{Complications}

Throughout this period of follow-up, patients complained of and were treated for various complications. Altered vision occurred in 14 eyes $(8.9 \%)$ at a median time of 248 days postoperatively (time of first mention in the file). The problem resolved spontaneously in three patients (in up to 49 days). One case of post-traumatic mydriasis was said to have resolved after three years because file notes indicate isocoric pupils at that time. Two cases necessitated the removal of the prosthesis or another type of ophthalmological intervention. For most cases (64.3\%), the complication persisted at the term of patient follow-up (which occasionally corresponded to the end of the study) (Figure 4).

Diplopia was a common complication affecting 27 patients (17.1\%). Ouadah et al (2) found that $18.8 \%$ of patients ( 80 over five years) were affected by diplopia. The median time of apparition was 19 days postoperatively, but some patients only mentioned this problem 15 years after the intervention. This complication stopped troubling the patient after an average of 522 days for $29 \%$ of patients. Extraction of the prosthesis was required in $19.2 \%$ of patients. Another $19.2 \%$ necessitated a subsequent bony graft. Unfortunately, the problem persisted for $46.1 \%$ of patients (some after a second surgery). Reintervention was required for $6.6 \%$ of all or- 


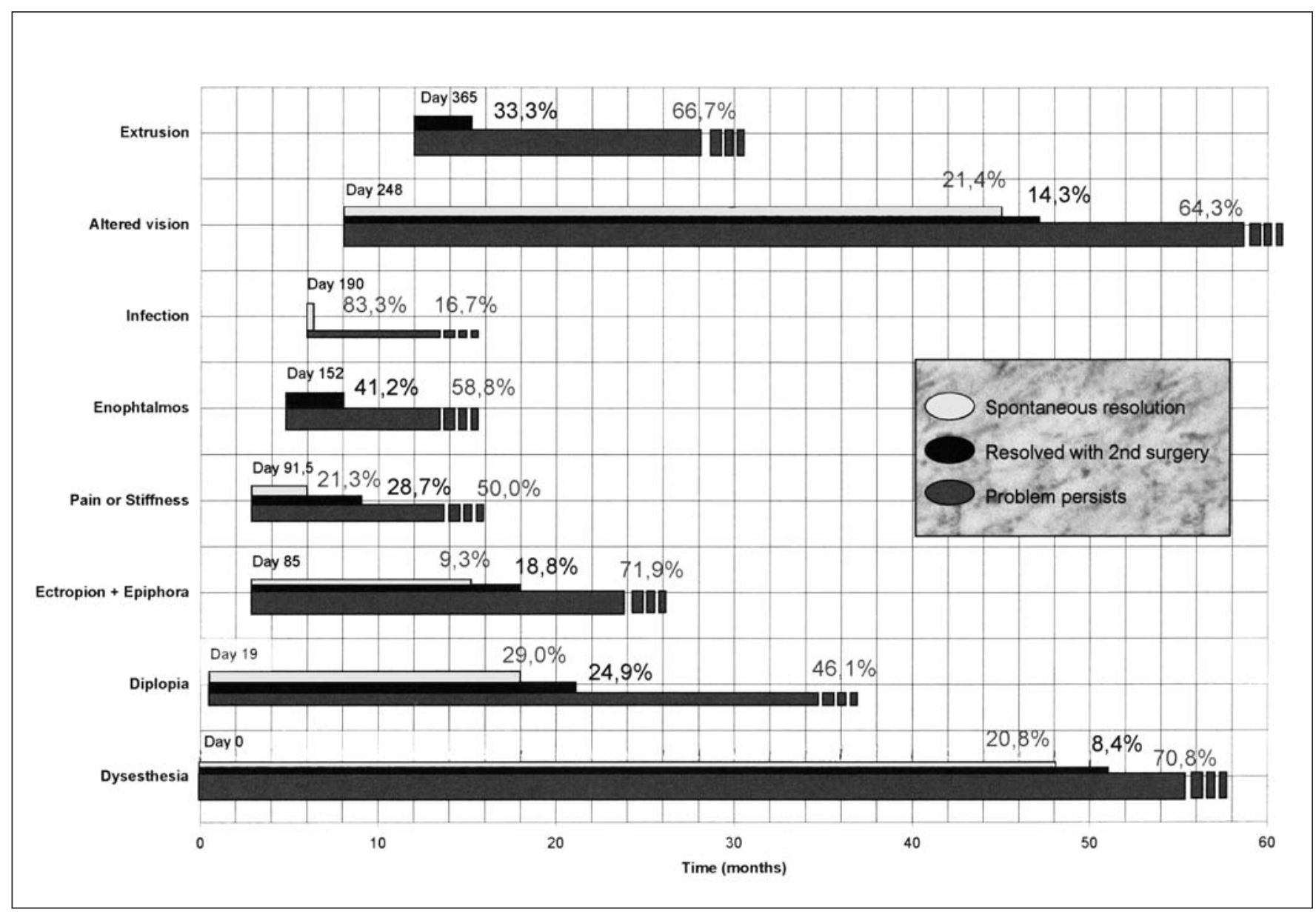

Figure 4) Complications observed in patients with orbital floor fracture repairs seen at Centre Hospitalier de l'Université de Montréal, Hôpital Notre-Dame between 1983 and 1992

bital floor fractures because of diplopia. The literature shows rates of reintervention for diplopia varying from $1.3 \%$ to $13.8 \%(2-4)$.

Dysesthesia appeared in 25 cases (15.8\%), usually on the first postoperative day (although some mentioned it only after 384 days). Resolution occurred in $20.8 \%$ of patients' eyes at an average of four years postoperatively. Two eyes required prosthesis extraction or neurolysis. For the other patients (70.8\%), the loss of sensation continued at the end of follow-up.

The most common complications were ectropion or epiphora, which occurred in 35 eyes $(22.2 \%)$. These two complications were related in most cases. There was one case of epiphora explained by nasolacrimal duct obstruction and eight cases in which tearing was subjective. The median time of appartition was 85 days after surgery. Yet, some patients noticed one of these two problems the morning after surgery, and other patients noticed it only after 8.7 years. Resolution of ectropion or epiphora occurred spontaneously for only $9.3 \%$ of patients (on average, one year later). In some cases, some type of intervention (ie, ectropion repair, tarsorraphy) was required (12.5\%). The prosthesis had to be removed in two cases $(6.3 \%)$. In $71.9 \%$ of patients, the complications remained unresolved.

Pain or stiffness was mentioned in 14 cases $(8.9 \%)$. For many patients, this discomfort was associated with the cold of the first winter. This discomfort occurred 91.5 days (median) into follow-up. The variability of this number depended on the time elapsed from surgery to winter. The ache disappeared after 99 days, on average $(21.3 \%)$, roughly the duration of the season. In other patients, the plate had to be removed or replaced with a bone graft. Two patients required dermabrasion. Pain remained for $50.0 \%$ of eyes at the term of patient follow-up (which occasionally corresponded to the end of the study).

Infection was identified in six eyes (3.8\%). This was diagnosed at approximately 190 days (median). Spontaneous resolution or resolution due to antibiotic therapy (seven to 10 days duration) occurred in $83.3 \%$ of patients. Chronic infection persisted in one patient.

Enophthalmos was noted in 17 patients $(10.8 \%)$. This complication was first mentioned at a median time of 152 days postoperatively (five months). This problem was a common indication for subsequent bone grafting, which was required in six patients $(35.3 \%)$. The problem persisted in slightly more than one-half $(58.8 \%)$ of the eyes with this complication, even after grafting in two patients.

Prosthesis extrusion was the least likely complication. It occurred in only three eyes $(1.9 \%$, three patients) approxi- 
TABLE 2

Variables and complications of patients with orbital floor fracture repairs seen at Centre Hospitalier de I'Université de Montréal, Hôpital Notre-Dame between 1983 and 1992

\begin{tabular}{|c|c|c|c|c|c|c|c|c|}
\hline & Altered vision & Diplopia & Dysesthesia & $\begin{array}{c}\text { Ectropion } \\
\text { and epiphora }\end{array}$ & Pain & Infection & Enophthalmos & Extrusion \\
\hline Age & $\begin{array}{c}\mathrm{D} \\
(\mathrm{P}=0.0106)\end{array}$ & & & & & * & & $*$ \\
\hline Trauma to surgery time lag & & & & & & * & & * \\
\hline Surgeon & & & & & & $*$ & & * \\
\hline Length of surgery & $\begin{array}{c}\mathrm{D} \\
(\mathrm{P}=0.0381)\end{array}$ & & & & & $*$ & & * \\
\hline Antibiotic prophylaxis & * & * & $*$ & * & * & & * & * \\
\hline Type of material & & $\begin{array}{c}X \\
(P=0.0275)\end{array}$ & & & $\begin{array}{c}X \\
(P=0.0473)\end{array}$ & & & * \\
\hline
\end{tabular}

*Calculations were not done in these cases mainly because of an insufficient number of subjects or because the analysis was irrelevant. $X$ indicates that the variable presented in the left column has an influence on the incidence of the corresponding complication. D indicates that any increase in the probability of a complication is directly proportionate to the increase of the corresponding variable in the left most column

\section{TABLE 3}

Variables and complications of patients with orbital floor fracture repairs seen at Centre Hospitalier de l'Université de Montréal, Hôpital Notre-Dame between 1983 and 1992

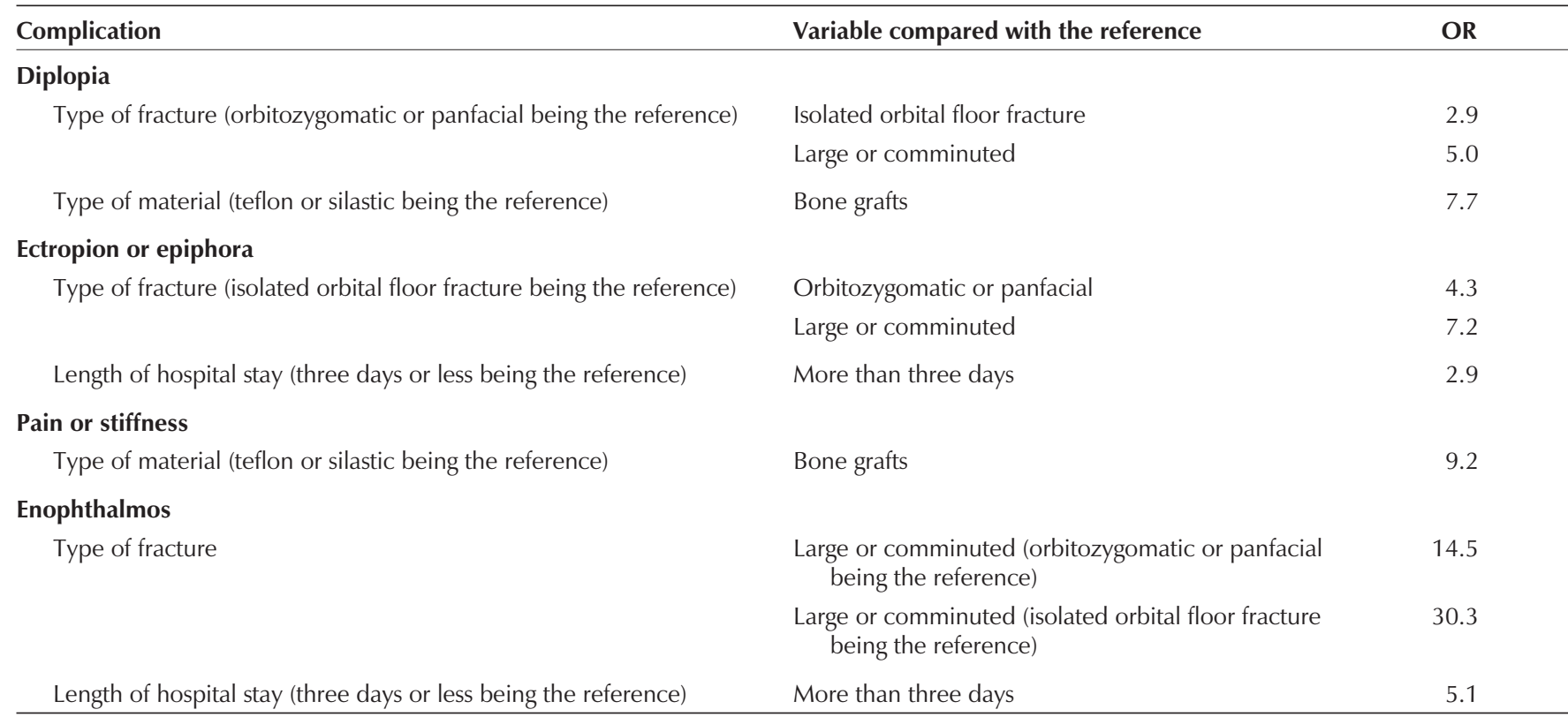

mately one year after surgery. One patient required a bone graft, the other two remained with this anomaly.

\section{Complications related to variables}

The complications that occurred in a sufficient number of eyes underwent further statistical analysis. The probability of altered vision was significantly related to age $(\mathrm{P}=0.0106)$. The older the patient, the more likely his or her vision was to change. Altered vision was also more likely to occur with an increased length of surgery $(\mathrm{P}=0.0381)$ (Tables 2,3$)$.
Diplopia was influenced by the type of fracture, $\mathrm{P}$ was significant at 0.0102 . OR calculations indicated that diplopia was 2.9 times more likely to occur with an isolated orbital floor fracture compared with orbitozygomatic or panfacial fractures. The complication occurred five times more frequently with large or comminuted fractures than with orbitozygomatic or panfacial fractures. Diplopia was least likely associated with orbitozygomatic or panfacial fractures. The incidence of this complication was also modified by the type of material used to rebuild the orbital floor $(\mathrm{P}=0.0275)$. Bone 
grafts were 7.7 times more likely to be associated with diplopia than with teflon or silastic prostheses.

Dysesthesia of the infraorbital skin was not significantly affected by any of the variables studied.

Ectropion or epiphora was significantly related to the type of fracture $(\mathrm{P}=0.0489)$. Orbitozygomatic or panfacial fractures were 4.3 times more likely to incur these difficulties than isolated orbital floor fractures. If a large or comminuted fracture, rather than an isolated orbital floor fracture, was found, the likelihood of complication was 7.2 times greater. Therefore, isolated orbital floor fractures cause the least amount of ectropion or epiphora. The length of hospital stay was significantly associated with the occurrence of ectropion or epiphora $(\mathrm{P}=0.0095)$. If hospitalized for more than three days, the patient had 2.9 times more risk of encountering these problems compared with shorter durations.

Pain was significantly linked to the type of material used for the prosthesis $(\mathrm{P}=0.0473)$. Metallic and other types of prostheses had to be excluded from this analysis because there were no complications in that category. Consequently, pain was found to be 9.2 times more likely to occur with bone grafts compared with teflon or silastic prostheses.

Infection was analyzed using two variables: antibiotic prophylaxis and the type of material used for repair. An 8.6\% (three cases) infection rate was found when topical or no prophylaxis was used compared with a $2.4 \%$ (three cases) rate of infection when systemic antibiotics were used. OR calculations yielded no statistical difference between these groups. Likewise, the infection rate was not significantly altered by the type of material used for orbital floor fracture repair.

Enophthalmos was very significantly associated with the type of fracture encountered $(\mathrm{P}=0.0001)$. The risk of this complication was significantly greater with large or comminuted fractures: 14.5 times that of orbitozygomatic or panfacial fractures and 30.3 times that of isolated orbital floor fractures. Length of hospital stay was also significantly linked to enophthalmos $(\mathrm{P}=0.0039)$. If hospitalized for more than three days, the patient's risk of enophthalmos was 5.1 times greater (according to OR calculations).

\section{DISCUSSION}

Orbital floor fractures seem to be an affliction of young men, just like all types of trauma. Repair is a fairly simple procedure. Teflon or silastic prostheses are usually chosen but the main indications for the use of bone grafts in the present study was for large or comminuted fractures or for a substantial loss of bony substance (especially if reconstruction of another surface, eg, sinus, was required). Primary bone grafts were used in $26.3 \%$ of large or comminuted fractures. Bone grafts were also used to treat persistant complications, such as diplopia, pain, enophthalmos and prosthesis extrusion, after primary repair. Hence, secondary grafting occurred in another $26.3 \%$ of large or comminuted fractures (all but one case involved this type of fracture). Therefore, over $50 \%$ of large or comminuted fractures required bone grafting. Because orbital floor fractures were often part of polytraumatic cases, concommitant serious injuries to the rest of the body were not uncommon. Accordingly, the following variables may have been artificially altered: length of surgery, length of hospital stay, follow-up and prophylactic use of antibiotics.

\section{Complications in time}

The most common complications encountered in the present study were ectropion and epiphora, diplopia, dysesthesia and enophthalmos. Fittingly, these are the classic complications associated with orbital floor fractures. Dysesthesia and diplopia are the first complications to appear (Figure 4) because they result from the mechanical forces of trauma or surgery (neuropraxia, axontmesis, extraocular muscle displacement). Ectropion and epiphora, and pain and stiffness may result from scarring because both fall into the remodelling phase of normal wound repair when collagen cross-linking occurs. Enophthalmos is noticed about six months into follow-up because the problem progressively worsens due to decreased swelling and contraction of soft tissue (5). Infection occurred sporadically, which is usually the case in the normal eye. Vision is affected more slowly, possibly because patients only notice the problem once all of the other annoyances have been resolved or because some of the ophthalmological problems, such as cataract, glaucoma or optic atrophy, progress slowly until they cause impairment $(6,7)$. Extrusion was the last complication to develop (about one year after surgery). It was always associated with alloplastic material that is not as stable as a bone graft (2) and may dislodge from its location after one year.

Resolution was rare but occurred without surgical intervention in about one of four complications. For example, resolution occurred after four years in some cases of dysesthesia. Just enough time for axons to regrow. In contrast, infection was eradicated rather easily after seven to 10 days in $83.3 \%$ of patients. Surgical reintervention was curative for another one of three complications (many times by removal of the implant). Secondary bone grafts were used effectively in five cases. Unfortunately, the troubles continued for a considerable number of eyes at the term of patient follow-up (which occasionally corresponded to the end of the study): $16.7 \%$ to $71.9 \%$, according to the type of complication (Figure 4). Some of the latter percentages may be higher because of insufficient follow-up. With the last information gathered from the patients, it can be stated that 58 patients had some kind of ongoing problem and 90 patients had none. Therefore, $39.2 \%$ of all patients who had undergone orbital floor fracture repair will have long term unresolved complications (some patients will have more than one complication per eye).

\section{Complications related to variables}

Some of the above morbidity may be prevented by acting on some of the variables that factor into each complication.

Altered vision is more probable with older patients. Trauma or surgery may accelerate an age-linked pathological process such as cataract. Tissues may be more frail or healing less efficiently. Normal evolution of vision with age is elimi- 
nated as a possible explanation for the relationship between age and altered vision because this is usually a bilateral condition. The number of subjects with this complication is insufficient to determine whether altered vision is also proportionately linked to age within an age group (eg, 15- to 45 -year-old patients) or if this relation only exists when the oldest patients are compared with the younger ones.

Also, the longer the surgery, the more likely the patient is to experience altered vision. This complication is not linked to older age because patients who underwent longer surgeries were generally in their 20s. Extensive trauma could explain altered vision and longer surgical time but one must discard this hypothesis because vision was not influenced by the type of fracture (a good indicator of the severity of trauma). It must be considered that longer surgeries result in extended periods of globe retraction, which could lead to increased intraocular inflammation, ischemia or added stress to the eye. These factors can explain all of the etiologies linked to altered vision (for example, anterior chamber inflammation is a cause of glaucoma).

With progressive difficulties, such as cataract, glaucoma or optic atrophy, it is difficult to determine whether sequelae resulted from trauma or surgery. When more acute problems, such as corneal abrasions, refractive errors or retrobulbar hemorrage occurred, they were only included in the present study if they occurred after the surgery or should have been corrected by it.

Diplopia was least likely to occur with orbitozygomatic or panfacial fractures compared with isolated orbital floor fracures $(\mathrm{OR}=2.9)$ and large or comminuted fractures $(\mathrm{OR}=5.0)$. Force is probably transmitted more directly to the orbital floor, causing a more destructive blow in the isolated orbital floor fracture rather than channelling the force of the blow through other facial structures, as is the case in the first types of fractures discussed. This hypothesis supports theories that state that blowout fractures are caused by a sudden increase in intraorbital pressure from the application of force directly on the globe (5). Another possibility is that a direct force to the eye causes monocular diplopia (dislocated lens, macular edema with metamorphopsia), although this was never specifically stated in the patients' charts. As for the large or comminuted fracture, the present study considered it to be the most severe type. Therefore, it was more likely to displace bony structures and cause incarceration of extraocular muscles. This also suggests that a more severe injury may damage muscle or connective tissue, which will continue to cause diplopia even when soft tissues and bone fragments have been restored to their original location.

Diplopia was a more common outcome with bone grafts as opposed to the use of teflon or silastic prostheses for orbital floor fracture repair $(\mathrm{OR}=7.7)$. These differences relate to size and texture. Bone grafts generally cannot be made to be as thin and smooth as alloplastic sheets, and are oversized to compensate for anticipated resorption. These factors may alter extraocular muscle motility. However, it should not be forgotten that large or comminuted fractures are more prevalent when grafts are used and that may be the reason for the increased occurrence of diplopia. A graft was used in only one case in which the fracture was not large or comminuted. During the chart review, special care was taken to search for large or comminuted fractures in every case. Unfortunately, bias may have been introduced because scrutiny was possibly more intensive in cases where grafts were used.

Dysesthesia was not significantly influenced by any of the variables studied, indicating that the likelihood of this complication is intrinsically similar in all orbital floor fractures that require surgical repair.

The occurrence of ectropion and epiphora increased with the overall severity of a fracture. Compared with isolated orbital floor fractures, there was a 4.3 time greater chance of a complication with orbitozygomatic or panfacial fractures and a 7.2 time greater chance with large or comminuted fractures. By definition, isolated orbital floor fractures usually do not cause musculocutaneous or lacrimal duct trauma. Ectropion complications in isolated fractures must, therefore, be iatrogenic, however, they are rare. When isolated, a fracture is not repaired with screws and plates that could induce more scarring and ectropion. With more extensive damage, the risk of complication also increases because of more manipulation and cutaneous incisions during surgery that contribute to cicatrization and ectropion. The risk of obstruction of the nasolacrimal duct is obviously greater when facial structures are involved. Injury to cranial nerve VII (causing ectropion or exposure) is least likely to occur with isolated orbital floor fractures. The same conclusion applies to cranial nerve $\mathrm{V}^{\mathrm{I}}$; an injury predisposes the patient to neurotrophic keratitis. This condition diminishes the protective effect of the lacrimal film on the eye's surface (dry eyes were included in this group of complications). Injury to the lacrimal gland is also more likely with more severe fractures.

Ectropion and epiphora were 2.9 times more probable if length of hospital stay surpassed three days. Because these complications are not influenced by trauma to surgery time lag, the finding must result from the severity of trauma (which influences both hospital stay and the complication).

Pain was only influenced by one variable, the use of bone grafts (pain was 9.2 times more likely with bone grafts than with alloplastic material). Assuming this influence is due to the severity of the trauma would be wrong because the type of fracture did not significantly influence the complication (although that could be explained by an insufficient number of patients). The pain or stiffness may be explained by the plates and screws that were necessary to hold the osseous graft in place. Thinner alloplastic material is possibly less irritating.

Enophthalmos correlated well with large or comminuted fractures. They were 14.5 times more likely than orbitozygomatic or panfacial fractures and 30.3 times more likely than isolated orbital floor fractures to cause this complication. This occurence, once again, denotes severity and demonstrates the effects of comminution or a gaping hole on the position of the eye (enophthalmos is more likely to occur with a medial wall fracture present) (5). It is easier to re-establish the normal morphology of the orbit when faced with less 
complex fractures. One cannot assume that the apparent enophthalmos is due to a distortion of facial bones because there is no significant difference between the incidence of enophthalmos in isolated orbital floor fractures and orbitozygomatic or panfacial fractures (even though the difference between large or comminuted and orbitozygomatic fractures $[\mathrm{OR}=14.5]$ is less marked than that with isolated orbital floor fractures $[\mathrm{OR}=30.3])$. It also seems important to point out that this complication was not affected by the use of bone grafts that are generally thought to be easily resorbable, which may induce late enophthalmos. All cases of enophthalmos found in the second chart review were linked to large or comminuted fractures, whereas orbitozygomatic or panfacial were the fractures associated with enophthalmos in the first chart review. Many orbitozygomatic or panfacial fractures may have been large or comminuted fractures that were not classified as such in the 1994 paper (1) (because this was not important for the end-points of that study). One can extrapolate that isolated orbital floor fractures and orbitozygomatic or panfacial fractures are relatively similar in terms of the incidence of enophtalmos (the inflated numbers found for orbitozygomatic or panfacial fractures may be due to the increased influence of large or comminuted fractures, and this may also apply to diplopia and ectropion or epiphora). All but one case of enophthalmos that required reintervention, such as bone grafting or plate removal, had initial large or comminuted fractures. This may indicate that when enophthalmos occurs in these cases, it is more severe.

When hospitalized for longer than three days, the risk of enophthalmos was 5.1 times greater than that with shorter inpatient stays. Extensive fractures that produce this complication are undoubtedly associated with injuries that require longer inpatient care.

Infection and extrusion were the least likely complications, occurring in only $3.8 \%$ and $1.9 \%$ of patients, respectively. The present infection rate is comparable with that of other studies with infection rates of $1.3 \%(2)$ and $7.4 \%(8,9)$. However, the present study included bacterial conjunctivitis as a type of infection, and its occurrence may have been entirely due to chance, thereby artificially inflating the percentage. Only one of three extrusions was associated with infection. The present extrusion rate of $1.9 \%$ is similar to that found by Ouadah et al (2) (1.3\%).

There were no cases of postoperative proptosis. Complications related to postoperative proptosis were described in 12 cases by Stewart (10) in 1995.

While remembering that the results of the present study may be more relevant for orbitozygomatic or panfacial fractures because of their high incidence $(71.5 \%)$, and that some information was gathered directly from patients, which could lead to misinterpretation of complications, the following can be stated: sex, surgeon, and trauma to surgery time lag had absolutely no significant influence on the incidence of complications. Some researchers believe that surgery should be undertaken as soon as there are appropriate indications to maximize postoperative movement of the globe (11). It is also often stated that the best time to operate is after inflam- mation has resorbed but before fibrosis sets in (during the second week post-trauma) (5). The present study found that this had no bearing on future problems. Of course, a prospective cohort study may be more appropriate to reach this conclusion. Nevertheless, intervening before cicatrization greatly facilitates the surgery.

The factor that had the greatest impact on complications was the type of fracture. It influenced diplopia, ectropion or epiphora, and enophthalmos. The physician can check for monocular diplopia. He or she can try to lessen incisions and manipulate soft tissues during surgery to prevent ectropion. But this is mainly a noncontrollable variable. Because the influence of the length of hospital stay is highly dependent on the severity of trauma, shortening it becomes useless. Increasing length of surgery should lead the surgeon to limit ocular manipulation to minimize, if at all possible, any change of vision. The only other element that one may act on is the type of material used. Bone grafts did not display greater resorption, as is sometimes described $(12,13,14)$, but were found to increase pain and diplopia. Because infection and extrusion rates are very low, bone grafts provide no great advantage. Their use could be limited to cases requiring extensive reconstruction that cannot be satisfactorily repaired with alloplastic materials or for reintervention after the failure of these implants. This opinion is shared by the authors of many other studies $(2,12)$. The advantages of alloplastic materials include less complications, no donor site morbidity and decreased operative time (5). It should be kept in mind though that because secondary bone grafting (after a first attempt with alloplastic or other materials) is needed almost exclusively in large or comminuted fractures, as the present study has shown, one may reduce its necessity with more liberal use of primary bone grafting in this type of fracture. An interesting alternative is a biocompatible prosthesis, such as porous polyethelene (MedPore; Porex Surgical Inc, USA), which will vascularize over time and offer some of the benefits of bone grafts without the disadvantages.

\section{CONCLUSIONS}

In chronological order, the following complications may occur after orbital floor fracture repair: dysesthesia, diplopia, ectropion and epiphora, pain and stiffness, enophthalmos, infection, vision changes and extrusion. Long term unresolved complications were suffered by $39.2 \%$ of eyes. Some associations that were made in the present study are as follows.

- Older patients and longer surgeries increase the risk of visual impairment.

- While orbitozygomatic and panfacial fractures are the least likely to cause diplopia, bone grafts will increase its incidence.

- Severe fractures are associated with more tearing problems and ectropion than less extensive fractures.

- Bone grafts cause more postoperative pain than prostheses.

- Large or comminuted fractures were the main causes of enophthalmos.

- Infection and extrusion were very unlikely complications. 
- The incidence of dysesthesia seems to be fixed, not being influenced by any of the variables studied.

- Complication rates were not altered by the surgeon, the patient's sex or the time elapsed from trauma to surgery. Lessening ocular manipulation during longer surgeries may reduce vision changes but the only variable that can be modulated with more certainty is the type of material used to repair the orbital floor fracture. Alloplastic prosthesis should be used unless extensive reconstruction can only be managed with bone grafting. When faced with large or comminuted fractures, bone grafting is an interesting first choice. Compared with the previous series (1), after over 15 years of follow-up, the conclusions remain essentially the same.

ACKNOWLEDGEMENTS: PR Boulos and PG Harris thank Dr Marie-Claude Guertin who spent many long hours tabulating the results and brilliantly organized them in the statistical format that brought forth the conclusions. The authors would also like to thank Dr RP Delorme and Dr R Charbonneau for contributing their orbital floor fracture cases to this study. The photographs for Figures 1 and 2 were provided courtesy of Marc Blouin, CHUM, Hôpital NotreDame, and the photograph for Figure 3 was provided by the photographic archives of CHUM, Hôtel Dieu.

\section{REFERENCES}

1. Harris PG, Delorme RP, Charbonneau R, Ciaburro H, Frenette G. Teflon prosthesis in orbital floor fracture. Can J Plast Surg 1994;2:32-4.

2. Ouadah A, Gerard M, Malpuech F, et al. Le traitement des fractures du plancher de l'orbite: réfection par lame de Téflon. Rev Stomatol Chir Maxillofac 1998;99(Suppl 1):120-1.

3. Greenwald HS, Keeney AH, Shanon GM. A review of 128 patients with orbital fracture. Am J Ophthalmol 1974;78:655.

4. Lavergne P, Berrada K, Scheffer P, et al. Fracture du plancher orbitaire: le résultat de leur traitement au Centre Hospitalier intercommunal de Villeneuve St-Georges. XXXI ${ }^{\mathrm{e}}$ Congrès de Stomatologie et Chirurgie Maxillo-faciale. Marseille, France, September 19 to 22, 1989. (Presentation)

5. Weingeist TA, Liesegang TJ, Grand MG, et al. Basic and Clinical Science Course 1998-1999, Section 7. San Francisco: American Academy of Ophthalmology, 1998:106-8.

6. Weingeist TA, Liesegang TJ, Grand MG, et al. Basic and Clinical Science Course 1998-1999, Section 10. San Francisco: American Academy of Ophthalmology,1998:77-80.

7. Weingeist TA, Liesegang TJ, Grand MG, et al. Basic and Clinical Science Course 1998-1999, Section 11. San Francisco: American Academy of Ophthalmology,1998:50-1.

8. Polley JW, Ringler SL. The use of Teflon in orbital floor reconstruction following blunt facial trauma: a 20 year experience. Plast Reconstr Surg 1987;79:39-43.

9. Daieff CY, Flageul G, Benharoun C, Stern A, Grignon JL. A propos de la reconstruction de 56 planchers de l'orbite par lame de silastic, conclusions actuelles de notre experience. Ann Chir Plast 1977;22:279-83.

10. Stewart MG, Patrinely JR, Appling WD, Jordan DR. Late proptosis following orbital floor fracture repair. Arch Otolaryngol Head Neck Surg 1995;121:649-52.

11. Rubin PAD, Bilyk JR. Orbital Fractures and Traumatic Optic Neuropathy. The Lancaster Opthalmology Review Course 2000. Waterville, Maine, July 7, 2000. (Presentation)

12. Goldberg RA, Garbutt M, Shorr N. Oculoplastic uses of cranial bone grafts. Ophthalmol Surg 1993;24:190-6.

13. Laurie SWW, Kaban LB, Mullikin JB, et al. Donor site morbidity after harvesting rib and iliac bone. Plast Reconstr Surg 1984;73:933-8.

14. Fiukle DR, Kowamoto HK. Complications of harvesting cranial bone grafts. In: Proceeding of the 64th Annual Meeting of the American Association of Plastic Surgeons. Coronada, California, 1985:24 